International Journal of Agriculture, Environment and Bioresearch

Vol. 5, No. 01; 2020

ISSN: $2456-8643$

\title{
HYGIENE AND SANITATION AND HEALTH PROBLEM IN THE COMMUNE OF KPOMASSE (REPUBLIC OF BENIN)
}

\author{
Gabin A. TCHAOU \\ Institute of Geography and Regional Planning (IGATE) / UAC \\ Laboratory for Studies of Urban and Regional Dynamics (LEDUR) \\ https://doi.org/10.35410/IJAEB.2020.5465
}

\begin{abstract}
The commune of Kpomassè, in Benin, faces serious environmental problems that have a direct impact on the health of the population. The objective of this study is to identify the environmental problems related to hygiene and sanitation in the commune and to inventory the main diseases related to poor environmental management. To conduct this study, desk research was conducted, followed by direct observation of field survey and individuals interviews. The results obtained showed that sanitation infrastructures are rare in Kpomassè. More than 53\% of households still use water from unprotected wells, $1.9 \%$ use lake water for their toilet water, crockery and drinking water needs. This situation causes several diseases, the most frequent of which are malaria $(44.21 \%)$, acute respiratory infections $(16.06 \%)$ and gastrointestinal diseases $(13.17 \%)$.
\end{abstract}

To guarantee good health to the populations of Kpomassè, the town hall must encourage the multiplication of drinking water points in its territory and actively participate in raising the awareness of these citizens on environmental management and hygiene and work to install and environmental management and hygiene système.

Keywords: Environmental problems, drinking water, sanitation, hygiene, Kpomasse.

\section{INTRODUCTION}

Men's health depends on their ability to manage the interaction between their human and economic activities, the physical and biological environment (Gbèlèmè, A.P, 2017,42p). Environmental hygiene and sanitation are aimed at preserving and promoting health without threatening the integrity of the natural systems that condition this environment. Unfortunately, questions relating to the management of the environment through pre-collection, collection, removal of household waste and, by extension, environmental planning and management are among the most complex that urban managers have to answer because of of their effects on human health, sustainable development "(Attahi, K. 1995, p19). Today, environmental damage is widespread and increasing. The collection of household waste and the management of wastewater constitute the major difficulties encountered by the municipalities. These difficulties translate into an accumulation of household waste, erection, the proliferation of wild dumps and the stagnation of wastewater and rainwater in the absence of an adequate waste and wastewater 
management system. Household waste collection rates rarely reach 50\% (Nyassogbo K.G. 2005). The low rate of garbage removal and wastewater management in Kpomassè results in an unsanitary, unhealthy environment characterized by pollution as well as air, soil, underground living environment inhabitants. It is for this reason that it has been agreed that the health problem is no longer just the business of specialists in modern medicine, but the business of all, among whom, the environmental geographer is essential. In recent years, the health of populations has challenged environmental geographers and health geographers who are interested in the regional and spatial study of pathologies (Ahissin-Tossa, FV, 2005, p 38, Tchaou AG, 2008, p27 ). The close relationship between environment and health is well established (WHO, 2000, p118). In municipalities that do not have real sanitation structures and environmental education centers, such as Kpomassè, the situation is still alarming. It is therefore appropriate to study human behaviors that promote the proliferation of conditions such as malaria, diarrhea, acute respiratory infections and gastrointestinal conditions. It is a question of proposing some approaches to solutions in the face of uncontrolled landfills which are multiplying in the municipality in order to encourage a change in behavior.

1Presentation of the study environment

The municipality of Kpomassè is between the parallels $6^{\circ} 20^{\prime}$ 'and $6^{\circ} 39^{\prime}$ north latitude and the meridians $1^{\circ} 56$ 'and $2^{\circ} 07^{\prime}$ east longitude. It covers an area of approximately $305 \mathrm{~km} 2$ (Nangbé F., 2006, p20). It is bounded to the north by the municipality of Allada, to the south by the municipality of Ouidah, to the east by the municipality of Tori-Bossito and to the west by Lake Ahémé. Administratively, the municipality of Kpomassè has nine (09) districts, namely: Kpomassè Center, Aganmalomè, Agbanto, Dédomè, Agonkanmè, Dékanmè, Sègbéya, Sègbéhouè and Tokpa- Domè (Figure 1). These districts are subdivided into sixty-eight (68) villages. The municipality of Kpomassè has 67,648 inhabitants (INSAE, 2013). The population density is 187 inhabitants per $\mathrm{km} 2$. It is populated by a diversity of cultural social groups: AdjaPédah and assimilated (53.4\%), Fon (40.4\%), etc. (INSAE, 2013). The main economic activities of the town are agriculture, fishing, animal husbandry, trade, handicrafts, the exploitation of fuelwood, the processing of agricultural and fishing products, and the exploitation of sand. and gravel. 


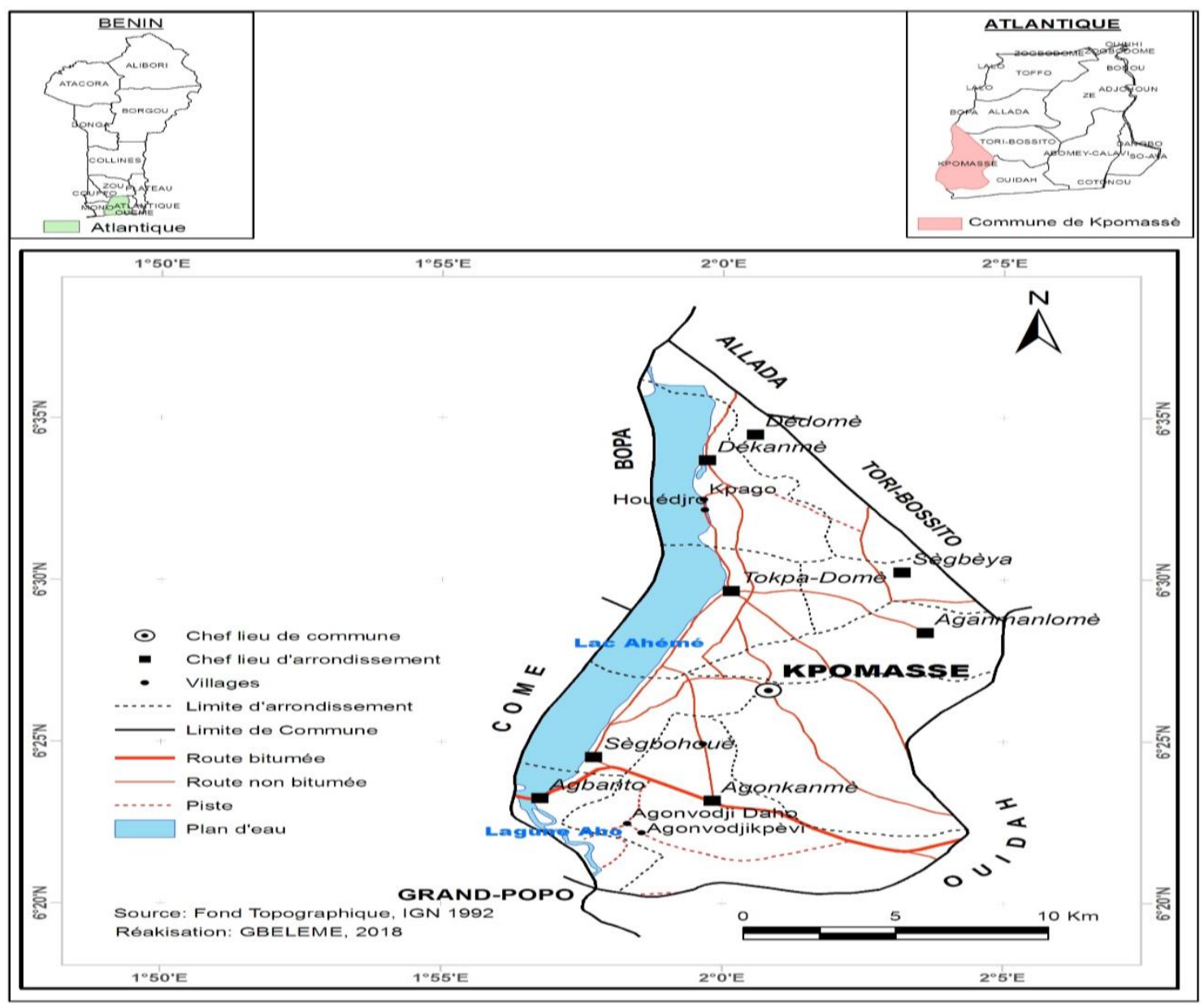

Figure 1. Presentation of the study area

The municipality of Kpomassè enjoys a four-season Guinean-Congolese climate (two dry seasons and two alternating rainy seasons) with an average rainfall of $1200 \mathrm{~mm}$ per year and an average temperature between $27^{\circ} \mathrm{C}$ and $31^{\circ} \mathrm{C}$. The relatively high humidity $(60 \%)$ is influenced by the large body of water that constitutes Lake Ahémé (Nangbé F., 2006, p24)

The hydrographic network consists of a permanent plan which is Lake Ahémé with an area varying from $78 \mathrm{~km} 2$ in low water to $100 \mathrm{~km} 2$ in high water (Nangbé F., 2006, p25). The water table has a depth varying between $34 \mathrm{~m}$ on the plateau and around $5 \mathrm{~m}$ around the lake.

At the pedological level, we have weak ferralitic soils, hydromorphic soils and tropical ferruginous soils. There are five (5) geological units that are gravels, sands and clays, fluvial deposits, quartz sands, clays, ferruginous sandstones, recent alluvial deposits, tidal and lagoon deposits.

The vegetation in the municipality varies according to the type of soil and the variation in the salinity rate of Lake Ahémé. So we have: 
- palm groves, consisting of shrubs varying in height from 2 to $2.5 \mathrm{~m}$, etc. on ferralitic soils

- a mosaic of marshy meadows and then the development of floating vegetation in the rainy season which disappears with the increase in salinity from January on hydromorphic soils.

- There are also the stands of red mangroves, white mangroves and then the mangrove fern which form an aquatic ecosystem.

We also have anthropogenic formations: fields, plantations (PDC, 2016).

\section{METHODOLOGY AND MATERIALS}

\subsection{Methodological approach to research}

Several documentation centers were visited and made it possible to collect information on the municipality of Kpomassè. These are the documentation centers of INSAE, Ex FLASH / UAC, FASHS / UAC and the town hall of Kpomassè.

The fieldwork was mainly limited to direct observation of the field and individual interviews. Thus, a few resource persons were interviewed for clarification questions and the perception of the populations on the relation "living environment and their state of health".

A digital camera is used for taking pictures. A motorbike is used for traveling between localities

\subsubsection{Sampling}

All the chief towns of the districts have been taken into account. The choice of resource persons is carried out by administrative authorities, opinion leaders, religious leaders and a few voluntary households chosen at random for the investigations.

Table 1. Summary of respondents and field observations

\begin{tabular}{|l|c|c|c|}
\hline Districts & Contacts & $\begin{array}{l}\text { Household } \\
\text { heads }\end{array}$ & $\begin{array}{l}\text { Total } \\
\text { household }\end{array}$ \\
\hline Agglomerate & 03 & 19 & 958 \\
\hline Agbanto & 03 & 21 & 1010 \\
\hline The bargain & 05 & 27 & 1318 \\
\hline Domestic & 04 & 21 & 1025 \\
\hline December & 05 & 29 & 1724 \\
\hline Serbia & 03 & 17 & 643 \\
\hline Sergeant & 04 & 23 & 1301 \\
\hline
\end{tabular}


International Journal of Agriculture, Environment and Bioresearch

Vol. 5, No. 01; 2020

ISSN: $2456-8643$

\begin{tabular}{|l|c|c|c|}
\hline Tokpa-Domè & 9 & 31 & 1720 \\
\hline Komomasser & 11 & 31 & 1842 \\
\hline Total & $\mathbf{4 7}$ & $\mathbf{2 1 9}$ & $\mathbf{1 1 5 4 1}$ \\
\hline
\end{tabular}

\subsubsection{Data collection}

To collect the data, techniques and tools were used. These are direct observation, interviews, using index cards, observation, interview guides and digital camera shots on:

- The management of household waste, garbage dumps, the proximity of houses to garbage dumps and the consequences of the proximity of garbage dumps to agglomerations by appropriate questionnaire

- Management of wastewater from household work.

\subsection{Data processing}

All the data collected were entered into the Excel spreadsheet and the creation of several graphs was carried out on sanitation and environmental hygiene.

\subsection{Data on main diseases linked to poor environmental management}

The determination of the main diseases linked to poor environmental management in Kpomassè required the collection of epidemiological data in public health centers. Thus, the epidemiological data relating to the various affections of the population of Kpomassè (20132017) were collected at the Ouidah-Kpomassè - Tori health zone hospital, at the municipal health center, in the health centers of the districts. Then, the PEIR (Pressure-State-Impact-Response) model grouping the data and information by level was used (Figure 2). It made it possible to analyze the current state of the environment and the living conditions of the populations, the pressure factors and the solutions to be envisaged. 


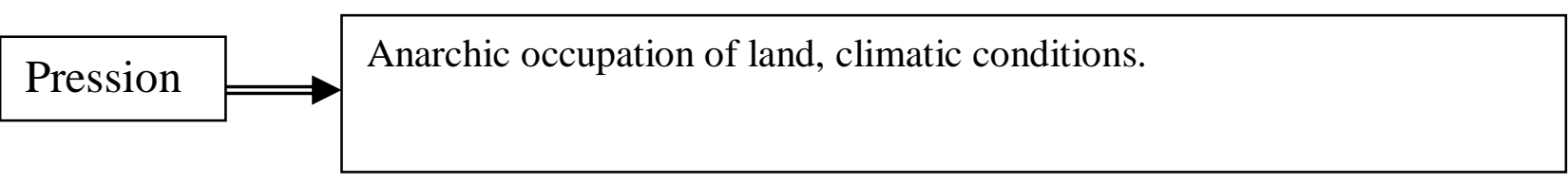

\begin{tabular}{|l|l|} 
State $\longrightarrow$ & $\begin{array}{l}\text { Degradation (precariousness) of the environment by poor management of } \\
\text { DSM and unhygienic behavior. }\end{array}$ \\
\end{tabular}

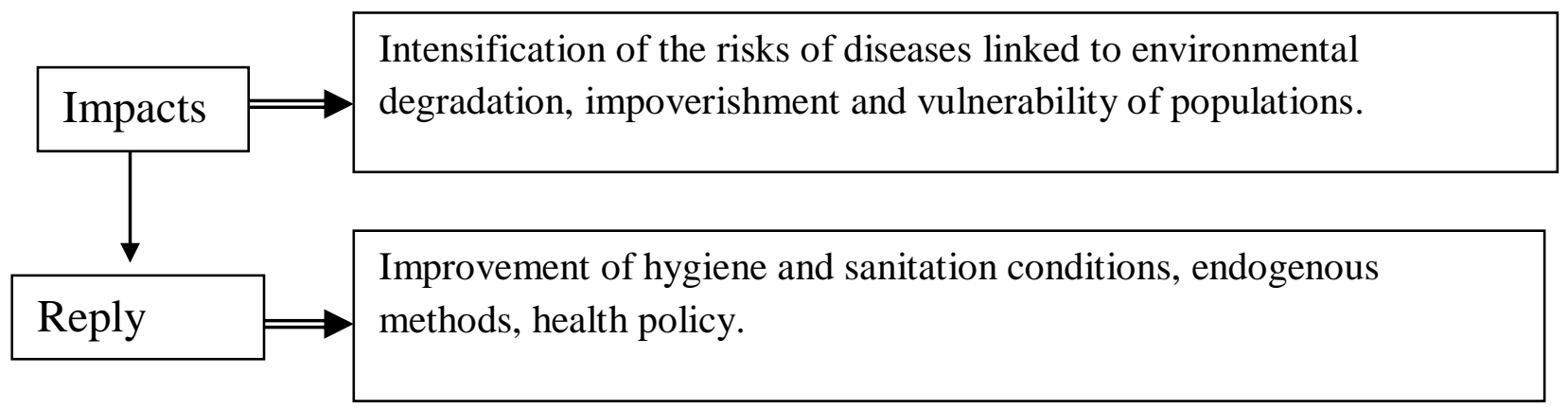

Figure 2. PEIR model applied to the relationship between the environment and the health of Kpomassè populations

\section{RESULTS}

\subsection{Environmental problems linked to the proliferation of diseases}

\subsubsection{Failed drinking water supply}

Most of the population does not have a source of drinking water. The water supply network covers only a tiny part of the Commune; the population uses well water, rain water, running water, but transported in containers which are sometimes not very clean and not covered (Photo1).

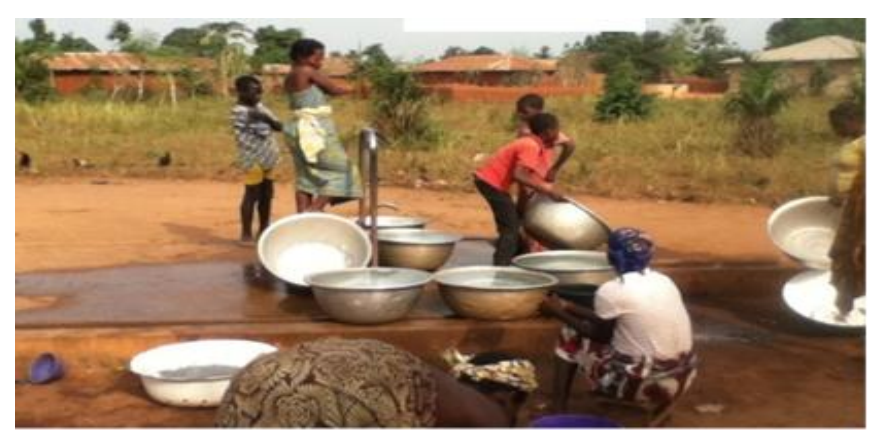

Photo 1. Drilling, drinking water point in Tokpa-Domè 
Vol. 5, No. 01; 2020

ISSN: $2456-8643$

Shooting: Gbèlèmè, June 2017

The water supply in the villages is provided by cisterns $(0.1 \%)$, wells $(68.44 \%)$, AEV (Village Water Supply: $15.9 \%)$ and the water supply network. water from SONEB (12.4\%) according to INSAE (2013).

Traditional uncovered and sometimes poorly maintained jars, cisterns and wells are the sources of proliferation of the vector agents of many diseases

In the district of Dékanmè, $45 \%$ of the heads of household interviewed go to the river for their water needs for their laundry and bathing needs (photo 2).

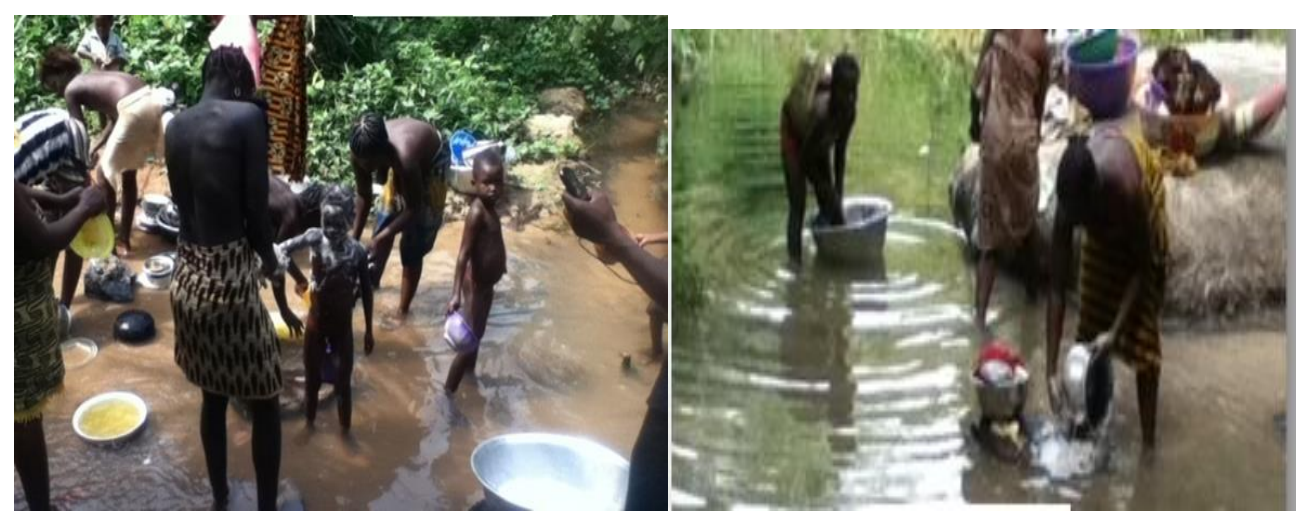

Photo 2a: Domestic use of the stream at Dékanmè (here bath)

2b: Dishes with water from Lake Ahémé in Sègbohouè

Shooting: Gbèlèmè, June 2017

The watercourses further contribute to the establishment of ecosystems favoring the proliferation of breeding sites. The fact that certain villages are located on the edge of Lake Ahémé exposes their population to significant health risks. The waters of Lake Ahémé are still used for several purposes (Photo 2b).

This lake is a source of water supply for residents of Ségbohouè but also for those of Dédomè, Dékanmè and Tokpa-Domè.

\subsubsection{Poor wastewater management}

Wastewater sometimes coming from domestic and economic activities (cooking, dishes, washing powder, showers, processing activities, restaurants / maquis / bars, etc.) is poorly disposed of. According to investigations carried out in the locality of Sègbèya, the inhabitants do not have a good knowledge of wastewater management. The majority (67.57\%) of the households surveyed dump waste water from domestic activities in the yard or near their homes and the rest (32.42\%) of households throw this unsanitary water on the rubbish heaps. This abandoned wastewater constitutes a shelter for anophelines, vector agents of malaria. 
Furthermore, with regard to wastewater from showers, the situation is crucial because $70.54 \%$ do not have cesspools in the urban center while $100 \%$ do not in the rural districts.

\section{1.3 Ease of living of the populations of Kpomassè}

Faeces are a source of pollution. The health risks they pose depend on the place of the toilet. The overall comfort mode remains traditional and harmful to health. Figure 3 shows the results of field surveys on people's welfare.

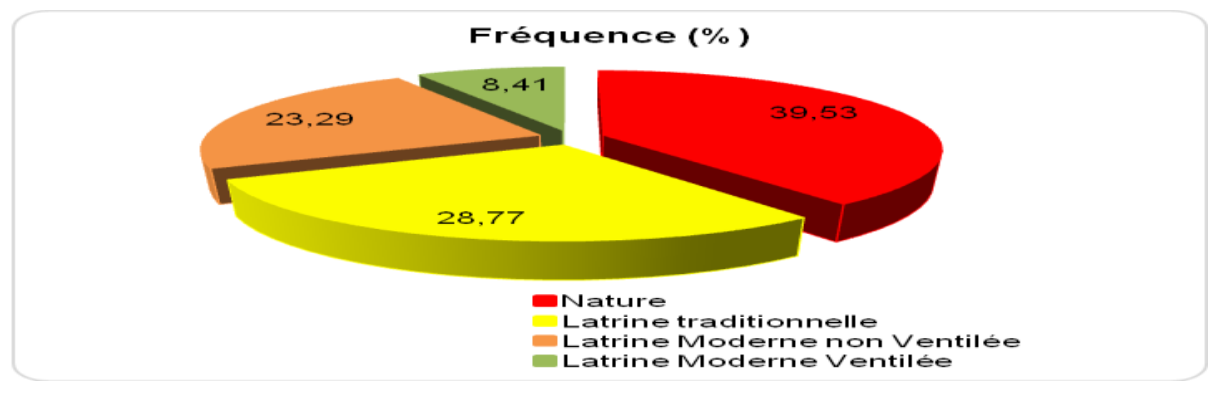

Figure 3: Affluence of the populations of Kpomassè

Source: Field survey results, May 2017

Modern ventilated latrines are almost non-existent in rural areas. Thus, there is a high risk of environmental pollution favorable to the outbreak of diseases due to fecal peril, to the spread of pathogenic vectors.

\subsubsection{Management of household waste}

Household waste produced in the municipality of Kpomassè is made up of biodegradable materials, recyclable materials and inert materials in the form of sand and stones. The components of the garbage have been classified into 9 essential elements: fermentable, plants (wood), plastics, metals, glass, textiles, paper (cardboard), fine particles (sand and ash) and stones. Biodegradable waste and non-degradable waste are found in garbage as shown in Photo5.

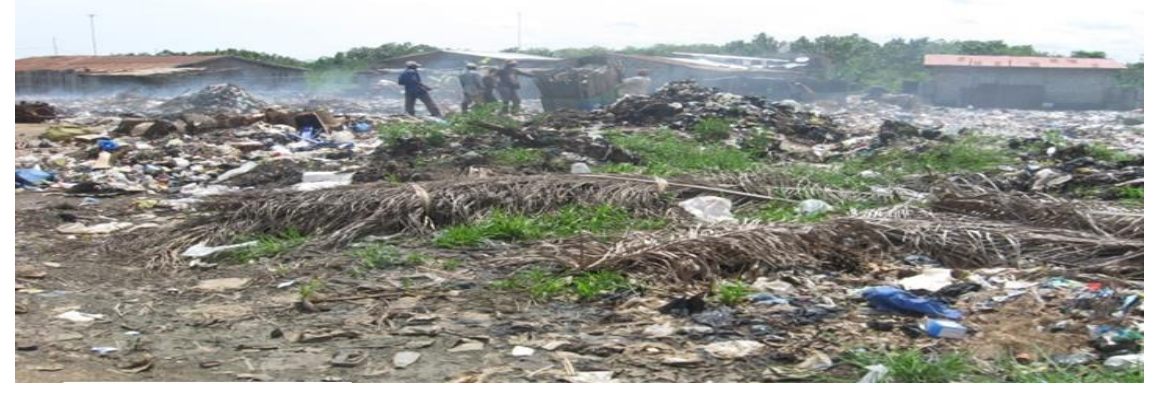

Photo 5: Hinzounmè dump in Tokpa-Domè, partly incinerated

Shooting: Gbèlèmè, June 2017 
This dump is located in the heart of Hinzounmè in the district of Tokpa-Domè. These wild dumps are increasing in volume and number, suddenly offering a distressing spectacle and maintaining visual and environmental pollution as shown in Figure 4.

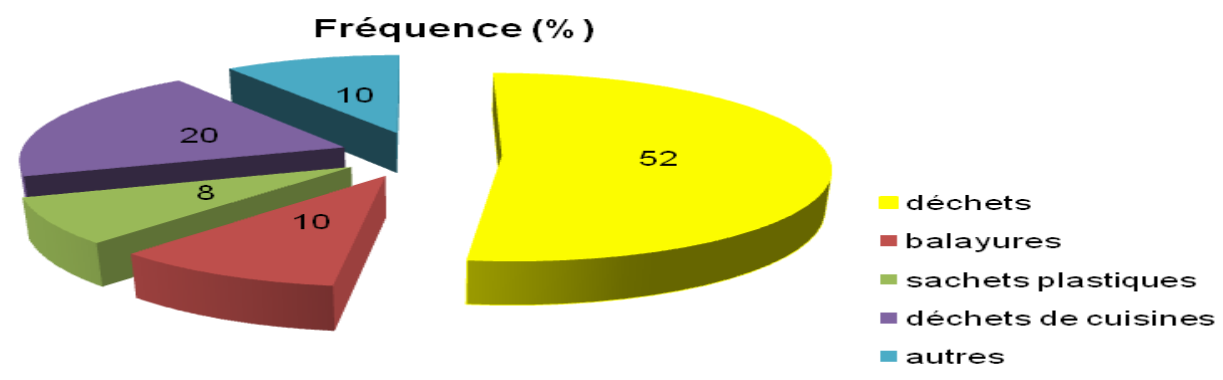

Figure 4 Waste categorization

Source: Field survey results, May 2017

In the commune of Kpomassè, there is almost no pre-collection structure and collection of solid household waste. The population throws the garbage on empty / vacant lots, in swamps and on wild dumps which can reach two (2) meters high and an area exceeding sixty (60) square meters (m2). Photo 6 shows the size of a garbage dump observed by in Kpomassè center.

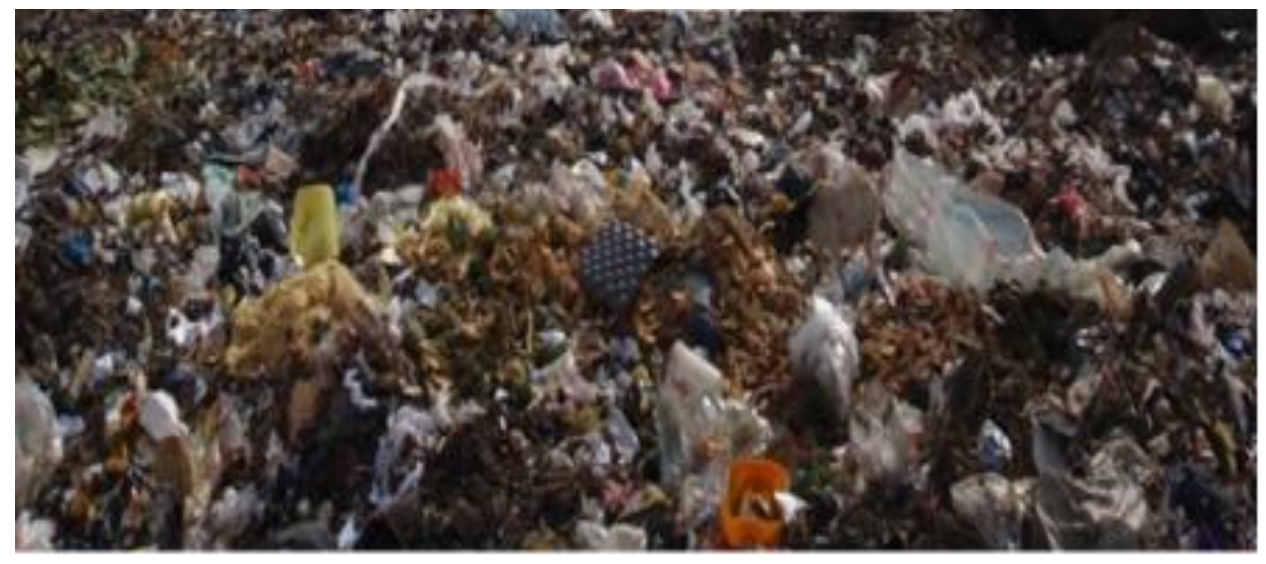

Photo 6. Wild dump in Kpomassè-center

Shooting: Tchaou, March 2017

Observation of this pile of garbage reveals that it does not contain homogeneous garbage. It is a mixture of biodegradable waste and non-degradable waste. When garbage dumps become too bulky, people burn them (Photo 7). 


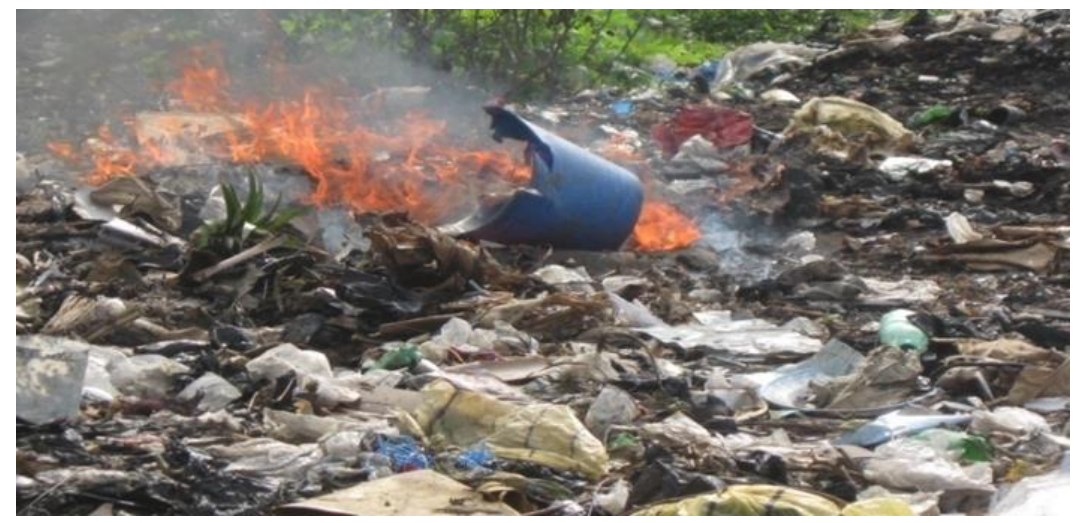

Photo 7: Burning garbage at the front of a house in Agonkanmè

Shooting: Gbèlèmè, March 2017

\subsubsection{Diseases linked to environmental management}

According to the epidemiological data collected at the Kpomassè municipal health center, at the Ouidah-Kpomassè-Tori zone hospital, the three diseases which are recurrent during the last five (5) years (2013-2017) are in order of importance, malaria, acute respiratory infections and gastrointestinal disorders (Figure 6).

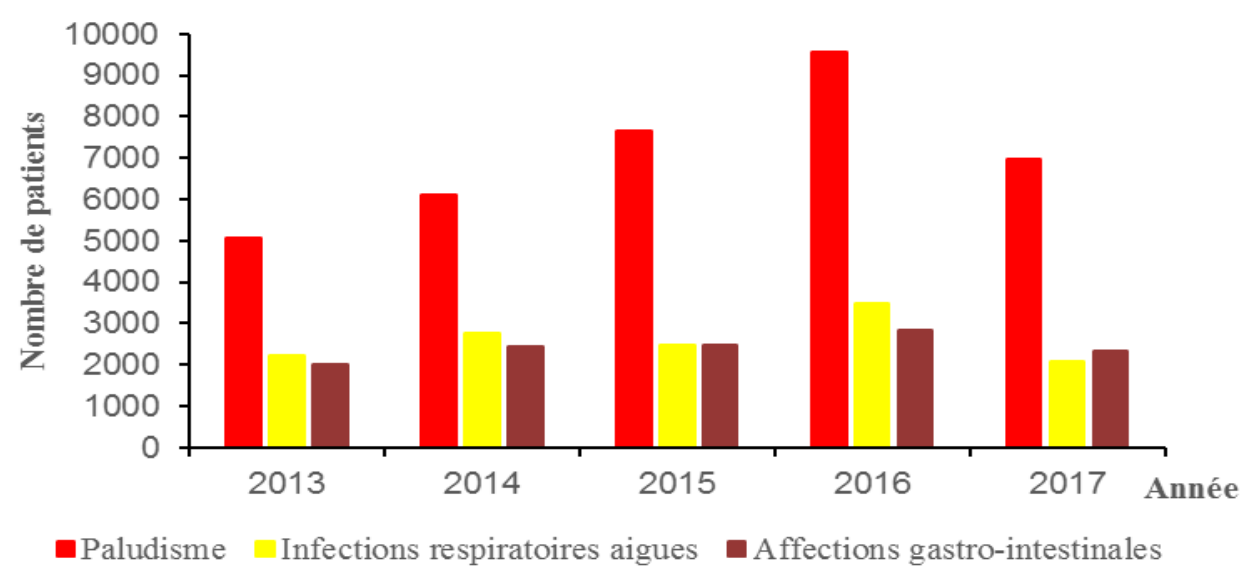

Figure 5. Variation of the most frequent illnesses in Kpomassè from 2013 to 2017

Source: Data from the Kpomassè municipal health center

The analysis of Figure 6 shows that malaria is at the top of the causes of health consultations in the period between 2013-2017 in Kpomassè. It increased from 5,053 in 2013 to 9,548 in 2016 and decreased from 9,548 to 6,984 from 2016 to 2017. Figure 6 shows the monthly variation in malaria between 2013 and 2017 


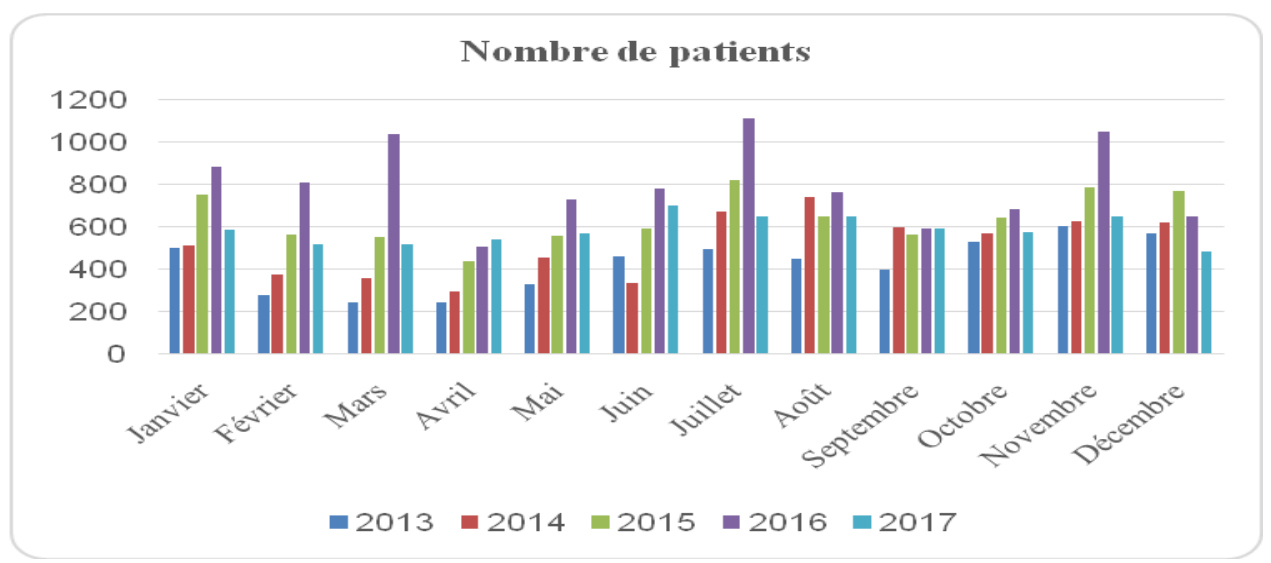

Figure 6. Variation in the number of people with malaria over the year

Source: Kpomassè municipal health center

From 2013 to 2017, the number of consultations for causes of malaria remained high every month. In addition, there is a very high rate of malaria, especially in the months of May, June, July and October, then drops from August, September, December, January, February and March. The peaks are often recorded in July and November. In 2016, we had a very high peak in March. It can be seen that the high rates of malaria are recorded during the two rainy seasons and during the short dry season and then at the start of the long dry season.

As for acute respiratory infections, these diseases also vary according to the months of the year (Figure 7).

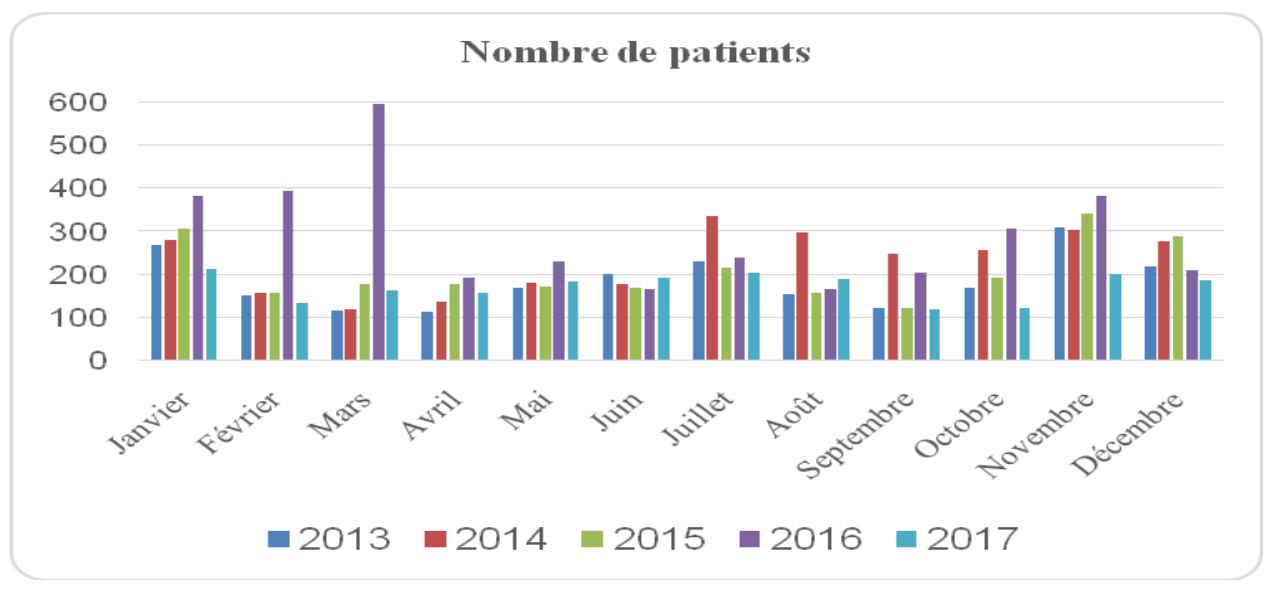

Figure 7. Monthly change in the number of people with acute respiratory infections from 2013 to 2017

Source: Ouidah-Kpomassè-Tori-Bossito Zone Hospital 
Acute respiratory infections are much more common in July, November, and January. These attendance rates are high except in 2016 where the high rates are recorded in the months of January, February, March, September, October and November.

Respiratory infections are very common and the smallest number of patients registered in a month is greater than or equal to 110 . We also note that the high rates are recorded during the long dry season and at the end of the long rainy season and at the beginning of the small dry season.

In terms of gastrointestinal disorders, the variation is not too remarkable during the year compared to the first two pathologies (Figure 8).

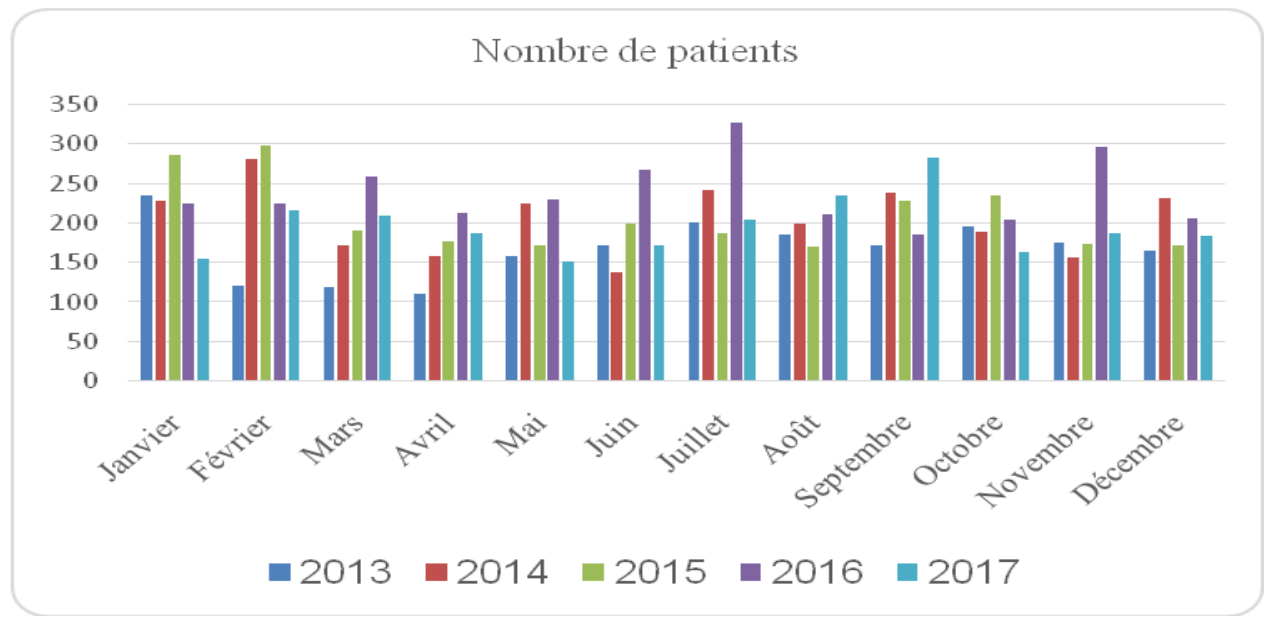

Figure 8: Variation in the number of people with gastrointestinal illnesses during the year

Source: Ouidah-Kpomassè- Tori-Bossito Zone Hospital

Gastrointestinal ailments are very common and elevated every month for five years. There is also a high rate of occurrence in the months of May to September.

\section{DISCUSSION}

\subsection{Problems related to water}

According to the WHO (1999), drinking water is water that does not contain pathogens or chemical agents in concentrations that can be harmful to health. The recovery rate of the water sector in Kpomassè as in several municipalities of Benin leaves something to be desired. The existing infrastructure is therefore insufficient in relation to the needs of the population in terms of drinking water. There are 824 inhabitants for a drinking water point (PDC, 2012) in the study area. This does not guarantee the populations of Kpomassè the minimum of 20 liters of water per inhabitant per day provided for by national standards. Over 53\% of households use water from unprotected wells, $15.30 \%$ use water from protected wells and $1.9 \%$ use lake water for their toilet, dish and drink water needs (PDC, 2012). This raises not only the problem of insufficient water points available, but also the problem of the quality of the water used. According to 
previous WHO research, polluted water contains germs that are responsible for many waterborne illnesses. The prevalence of waterborne diseases is often caused by different operating systems and / or water resource management methods. Likewise, in a study on the coastal region of Benin, Hêdiblè and Boko (2006) tackled the issue of degrading water quality and obtained the same results. The results have shown that all the water samples are contaminated with regard to accepted standards for drinking water. All in all, the diversity of socio-economic conditions and the main sources of water supply in the study environment could be determining factors for illnesses in populations. Despite the high cost of drinking water in the town, it is not always available, some sources are still of questionable or bad quality, which leads to illness.

In view of the results of Hêdiblè and Boko (2006), it is important to remember that the use of polluted water is very harmful, especially for children, who are more sensitive, fragile and vulnerable. Indeed, many children die every day from diarrheal diseases such as dysentery, typhoid fever and cholera. Polluted water is also the cause of dermatological diseases such as scabies. The toxic elements contained in polluted water can be preserved by plants whose subsequent consumption, by humans or animals, can cause digestive diseases and damage the liver and kidneys.

According to Sama (2006), improving the living conditions of populations requires the supply of drinking water and the promotion of hygiene and sanitation because, the most frequent pathologies are linked to water, 1 hygiene and sanitation.

All in all, the diversity of socio-economic conditions and the main sources of water supply in the study environment are determining factors of the affections among the populations of the commune. The use of improper water and unhygienic behavior are indicators that expose populations to the risk of multiple illnesses.

\subsection{Problems related to sanitation}

The situation of the living environment of the populations is a sensitive indicator of appreciation of their social well-being. This is why, since 1992, the WHO program for the promotion of environmental health has given itself the mission of devoting itself as a priority to the fields concerning the physical and social environment (WHO, 2000). Unfortunately, in Kpomassè, the management of household waste still needs to be improved for the good health of the populations.

The burning of plastic waste gives off abundant pollutants and foul smells harmful to health; like: black dust and fumes made up of carbon particles; carbon dioxide and nitrogen oxides which are greenhouse gases responsible for global warming; carbon monoxide, a gas toxic to humans and living organisms; volatile heavy metals (lead, mercury and cadmium,) which accumulate in natural environments and the food chain.

The presence of plastic bags in particular is a sign that people are becoming more and more trapped in this new way of life and are struggling to get rid of it.

\subsection{Approaches to solutions to diseases linked to the unhealthy environment}


Several guidelines set out basic guidelines for combating pollution. They serve as a frame of reference for the development of a policy to fight against pollution and the integration of the environmental dimension in all development actions. Grassroots populations should be more involved in the management of local resources. The indifference of citizens leads to huge dysfunctions within decentralized administrations. This is the case of the commune of Kpomassè like many others, which has a development plan which seems to be out of line with the commune's budget. Articles 65 and 73 of the framework law on the environment in the Republic of Benin deal with waste. They predict that waste must be adequately treated in order to eliminate or reduce to a required level their effects on human health, natural resources or the quality of the environment in general.

\section{At the individual / household level}

\section{Construction of latrines}

A significant part of the population of Kpomassè does not yet have this individual and collective sanitation facility and continues to go defecate in the wild. However, this practice is a source of pollution of the environment, proliferation of pathogenic germs and in turn negatively influences health. For those who have it, the non-existence of an emptying structure in the commune, the fixing of emptying prices in an anarchic manner by the emptying structures installed in the commune of Ouidah constitute a serious handicap for an efficient management of these emptying materials. .

The construction of septic tanks for the management of domestic wastewater

No form of treatment is reserved for these waters and they contribute to the pollution of the soil, the water table and rivers and water bodies. The construction of septic tanks per household will contribute to the reduction of the pollution of the environment and the affections relating to the bad management of these waters.

\section{CONCLUSION}

The municipality of Kpomassè has experienced a sharp increase in its population over the past ten (10) years. This demographic growth has led to the degradation of its environment, thus causing a negative impact on the health of the population.

Among the ailments suffered by the inhabitants, malaria, gastrointestinal ailments and acute respiratory infections are the most dominant with a much higher prevalence.

Poor hygiene and sanitation conditions, water supply problems, ecological parameters and the habits of populations create ecosystems favorable to the multiplication of pathogenic germs.

Larval breeding places abound everywhere and increase the mosquito population especially, in the rainy season and favor the proliferation of pathogenic vectors, viruses and bacteria, responsible for gastrointestinal diseases and acute respiratory infections. 
In light of the incidence and persistence of these conditions, people are developing prevention strategies and often resort to self-medication and traditional medicine before going to a health center. Despite the control efforts initiated

by health authorities, NGOs; there is still a reluctance on the part of populations to adopt behaviors aimed at improving their environment and their health.

\section{REFERENCES}

ABE, 1999. Framework law on the environment in Benin. 64 p.

Ahihou, L., 2006: Environment and health in the commune of Zogbodomey. Master thesis in Geography, FLASH / UAC, 94 p.

Ahissin-Tossa F. Virgile 2005: Environment and health problem in the commune of Savalou. Master thesis in Geography, FLASH / UAC, 79 p.

Attahi, K., 1995: The waste problem in Abidjan and its historical basis, BNETD, Abidjan. 29 p.

Gandji, Blandine., 2004: Environment and state of health of children under fifteen in the commune of Sô-Ava Master's thesis on geography 85 P.

Gbèlèmè A. Paulette (2017): Environment and health in the Municipality of Kpomassè in the Atlantic Department in Benin. Master thesis, 80p

Hêdiblè, Sidonie. Clarisse, and Boko, Michel., 2006: Problems related to the supply of drinking water in villages in the Atlantic department. In half-yearly scientific review published by LECREDE / FLASH / UAC, $\mathrm{N}^{\circ} 2$ June 2006, pp 32-47.

INSAE, 2013. Third General Census of Population and Housing; summary of analyzes in brief. Department of Demographic Studies, May 203. 48 p.

INSAE, 2016. Number of people in the villages and city districts of Benin (RGPH-4, 2013). February 2016. 85 p.

Kindjinou, André., 2009: Environment and epidemiological profile of children under 15 in the commune of Pobè. Master thesis in Geography, FLASH, UAC, 77p.

Mèdéou, Fidèle., 2009: Environmental determinants and childhood pathologies: case of malaria in children under five in the commune of Savalou. Master thesis in Geography, FLASH / UAC, $81 \mathrm{p}$.

Mekoun, C., 2010: Spatio-temporal dynamics of the dominant pathologies in Kpomassè's, master's thesis, FLASH / UAC 85 P.

Nangbé, Forentin., 2006: Monograph of the municipality of Kpomassè. Afrique Conseil, April 2006. 24 p. 
Nyassogbo, K. Gabriel, 2005: Accumulation of household waste and degradation of the urban environment. Some avenues for environmental sustainability in the African development process, Lomé (Togo), 19 p.

WHO, 2000. Our planet, our health: Report of the WHO Health and Environment commission. Geneva, 299 p.

PDC, 2012. Municipal development plan of Kpomassè (2012-2016); 82 p.

Sama, J., 2006: The problem of hygiene and sanitation in the face of drinking water consumption in rural areas in the Atacora department, DEA thesis, EDP / FLASH / UAC, 128p.

Tchaou A. Gabin, 2008: Factors associated with primary health care in the commune of Abomey-Calavi Republic of Benin; Master thesis Population in Health in Africa, Higher Institute of Population Sciences (ISSP) / University of Ouagadougou (UO) in partnership with the University of Montreal, 89p 